\title{
Factors related to non-mammographic visualization in locally advanced breast carcinoma
}

\author{
Anapaula Hidemi Uema Watanabe1, Marcio Mitsugui Saito1, \\ Bruno Eduardo Fernandes Cabral', René Aloisio da Costa Vieira1,2,3 (1)
}

\section{ABSTRACT}

Objective: To determine the rate and factors related to non-visualization of locally advanced breast cancer (LABC) by mammography. Method: Prospective, cross-sectional study, conducted in a cohort of consecutive patients with LABC treated at a tertiary cancer hospital. All patients were systematically examined and underwent high-resolution mammography (conventional equipment) in two views (craniocaudal and mediolateral oblique). A blind study was performed in which mammograms were mixed with routine and where radiologists were unaware of the clinical data. Three radiologists evaluated the examinations. In the patients in whom the findings were negative, the possible causes responsible for not identifying the tumor on mammography were evaluated. After the radiological report, the examinations were reviewed, and the radiological data were added to the standard form, making up the database of the present study. Descriptive statistics were used to compare factors related to non-visualization of tumors, namely the chi-square test and the Mann-Whitney test. Result: Eighty-five patients were evaluated. The average size of the tumors was $6.96 \mathrm{~cm}$, and $20 \%$ of cases were not identified on mammography. Among the causes, $76.4 \%$ had dense parenchyma, $17.6 \%$ were not visible on examination, and in $5.8 \%$, the lesion was not noticed by the radiologist (false negative examination). The only factor found when LABC was not identified was the type of breast parenchyma $(p=0.04)$. Conclusion: Clinical history and changes in physical examination should be considered in the report to the radiologist. High breast density was the major obstacle to mammography diagnosis.

KEYWORDS: breast neoplasms; mammography; predictive value of tests; diagnostic errors.

\section{INTRODUCTION}

Mammography is one of the main radiological modalities for the diagnosis of breast lesions. It is related to the reduction of breast cancer mortality ${ }^{1,2}$. However, about 10 to $30 \%$ of breast cancers may not be diagnosed on mammography, the possible causes being: dense breast parenchyma, errors in perception, incorrect interpretation of suspicious findings, tenuous characteristics of malignancy and slow growth of a lesion ${ }^{3-6}$.

In Brazil, there are several problems in mammographic screening, in which many patients, even if symptomatic, use mammographic screening campaigns of diagnostic task force to obtain diagnostic mammography.

Associated with this fact is that there is a delay in diagnosis along with the lack of appreciation of clinical complaints, and limitations of the health system, either because of the delay in mammographic results, associated with the quality of the mammography, or errors in the mammographic diagnosis process ${ }^{7,8}$. In patients who have gotten a mammogram properly, there can be issues such as interval tumors and the regular use of non-digital mammography? Thus, many factors can lead to a negative finding, which can have medico-legal implications.

Locally advanced breast cancer (LABC) is still common in our country ${ }^{79}$, mainly due to the lack of regular mammography, apart from difficulties in patient navigation to all diagnostic examinations ${ }^{10}$.

There is a lack of studies that assess the percentage of lesions that are not identifiable by mammography. The identification of the factors associated with the non-visualization of tumors, even in LABC, is of utmost importance, aiming at a better understanding of the late diagnosis and the underestimation of potential radiological findings, justifying the present investigation.

${ }^{1}$ Barretos Cancer Hospital - Barretos (SP), Brazil.

Botucatu School of Medicine - Botucatu (SP), Brazil.

${ }^{3}$ Muriaé Cancer Hospital - Muriaé (MG), Brazil.

*Corresponding author: posgrad@hcancerbarretos.com.br

Conflict of interests: nothing to declare.

Received on: 03/30/2019. Accepted on:12/11/2019 


\section{METHOD}

We conducted a prospective, controlled study in patients with LABC, seen at a tertiary oncology hospital of the Unified Health System (SUS); the study was approved by the Research Ethics Committee No. 135/2008, which was registered at www.clinicaltrials.gov, NCT 00820690. Patients with non-metastatic LABC were evaluated. Data were collected from June 2008 to December 2009.

All patients with stage III breast cancer were submitted to a diagnostic delay questionnaire, systematically being directed to clinical examination, new mammography and breast ultrasound.

The inclusion criteria were:

- Patients with LABC, non-metastatic, stage III;

- Eastern Cooperative Oncology Group (ECOG scale) 0 or 1;

- Confirmed diagnosis of invasive ductal or lobular carcinoma.

The exclusion criteria were:

- Patients with extensive peau d'orange;

- Pregnant women;

- Primary inflammatory carcinoma;

- Ulcerated tumor;

- Failure to sign the informed consent form.

The patients underwent high-resolution mammography using computerized radiography equipment in two views (craniocaudal and mediolateral). The images were sent blindly and independently to three radiologists with extensive experience who were unaware of patient data and physical examination. In addition, these patients underwent ultrasound with dedicated high-frequency transducers; this was to assess the correlation between clinical examination and imaging examination. The density of the parenchyma was divided into four categories: breast almost entirely fat, breast with scattering of fibroglandular tissues, breast heterogeneously dense, and beast extremely dense; this is the new classification by the Breast Imaging-Reporting and Data System (BI-RADS). In patients with negative findings, the possible causes responsible for the failure to identify the tumor on mammography were evaluated. After the radiological report, and later, the data related to the radiological findings were added to the form, making up the database of the present study.

The data were recorded on a standard form and digitized for evaluation using the IBM Statistical Package for the Social Sciences (SPSS) for Mac, version 22. Descriptive statistics of the patients and mammographic findings are presented in Tables 1 and 2. We tried to group the main findings and compare them with non-identification in the mammographic examination, aiming to evaluate potential causes for the lack of identification of the lesion (Table 3). The $\chi^{2}$ test was used to compare factors related to the non-visualization of tumors, and Fisher's test was used with values below 5 . Continuous variables were assessed using the Mann-Whitney test. Values below 5\% were considered significant.

\section{RESULTS}

Eighty-five patients, diagnosed with LABC, were evaluated. The main clinical findings are shown in Table 1. Mean age was 46.4 years (from 21.5 to 68.4 years). All patients were symptomatic and had a mean $( \pm$ SD) complaint time and tumor size of $12.2 \pm 11.6$ months and $6.9 \pm 2.5 \mathrm{~cm}$ ( 2 to $15 \mathrm{~cm})$, respectively. Of the total, $97.6 \%$ had unilateral involvement. Evaluating the clinical staging, $56.5 \%$ had stage IIIA, and $62.4 \%$ were T3, $72.9 \% \mathrm{N1}$ and $86.9 \%$ invasive ductal carcinoma.

Mammographic findings (Table 2) showed that $25.8 \%$ of patients had a dense or heterogeneous breast parenchyma. The main mammographic findings were the presence of a nodule (82.4\%), microcalcifications (38.8\%) and suspect lymph nodes (34.1\%).

Of the patients, 81 (96.4\%) underwent breast ultrasound. According to the echogenicity of the parenchyma, most were heterogeneous (45.7\%), showing an irregular nodule (77.8\%), with a hypoechoic pattern (93.8\%) and shadow (61.7\%) or posterior reinforcement (12.3\%).

Of the lesions identified on physical examination, 20\% ( $\mathrm{n}=17)$ were not diagnosed on mammography (Table 1). Among the causes, $76.4 \%$ had dense parenchyma, $17.6 \%$ were not visible on examination, and in $6 \%$, the lesion was not noticed by the radiologist (false negative). Figure 1 exemplifies a LABC case in which the tumor was not seen on mammography in a patient with a dense breast. Comparing the age group and the grouping of the main radiological findings, we found that the only and main factor associated with the non-identification of LABC was the type of breast parenchyma $(\mathrm{p}=0.04$; Table 3). Multivariate calculations were not performed because a single factor was identified with $\mathrm{p}<0.10$.

\section{DISCUSSION}

In general, the mammography examination in asymptomatic women is associated with a rate of non-visualization of lesions of around $10 \%$. The findings of this study are noteworthy, in which $20 \%$ of symptomatic patients with confirmed biopsy had a normal mammography examination. This fact denotes the importance of the clinical data (asymptomatic/symptomatic) associated with the mammographic examination, as well as the inclusion of clinical information ${ }^{8}$, since the radiological evaluation occurred blindly and since the radiologists were unaware of the patients' data.

There are barriers related to delayed diagnosis ${ }^{11}$ relating to the health system, which can lead to an increase in the time between examinations; these can be problems related to the quality of radiological examinations, socioeconomic status, and distance from the referral service. In places where there is a limitation for the performance of a mammogram by SUS, in the presence of joint efforts or in opportunistic screening, the patient is able to get a radiological breast assessment, with the aim of reaching the referral service faster ${ }^{8,12}$. This fact is associated with problems in the patient's navigation, that is, in undergoing additional 
tests until the definitive diagnosis of the neoplasm ${ }^{13}$, which is common in our country, where patients take a long time from the onset of symptoms to diagnosis, often requiring additional tests and then being sent to the referral service for treatment ${ }^{14}$. Evaluating factors against the patient, there may be radiological characteristics that hinder the clear mammographic visualization of the lesion and tumor doubling time ${ }^{15}$. In this case series, only patients with LABC were included. Although LABC may be associated with smaller tumors, with extensive axillary involvement (N2/N3), this portion represented only $20 \%$ of the sample, and the tumor size and lymph node involvement were not associated with non-visualization.

Table 1. Clinical parameters and main mammographic findings.

\begin{tabular}{|c|c|c|}
\hline Clinical finding & Parameter & Value (\%) \\
\hline Size & Mean (cm) & $6.9 \pm 2.5$ \\
\hline \multirow{3}{*}{ Age range } & $<40$ & $25(29.4)$ \\
\hline & 40 to 49 & $29(34.1)$ \\
\hline & $\geq 50$ & $31(36.5)$ \\
\hline \multirow{2}{*}{ Side } & Right & $29(34)$ \\
\hline & Left & $56(66)$ \\
\hline \multirow{2}{*}{ Laterality } & Unilateral & $83(97.6)$ \\
\hline & Bilateral & $2(2.4)$ \\
\hline \multirow{3}{*}{ T-TNM stage } & $\mathrm{T} 2$ & $1(1.2)$ \\
\hline & T3 & $53(62.4)$ \\
\hline & T4 & $31(36.5)$ \\
\hline \multirow{4}{*}{ N-TNM stage } & No & $6(7.1)$ \\
\hline & N1 & $62(72.9)$ \\
\hline & N2 & $14(16.5)$ \\
\hline & N3 & $3(3.5)$ \\
\hline \multirow{3}{*}{ TNM stage } & $\| \mathrm{A}$ & $48(56.5)$ \\
\hline & IIIB & $33(38.8)$ \\
\hline & IIIC & $4(4.7)$ \\
\hline \multirow{3}{*}{ Histology } & IDC & $73(86.9)$ \\
\hline & ILC & $5(5.9)$ \\
\hline & Others & $7(8.3)$ \\
\hline \multicolumn{3}{|l|}{$\begin{array}{l}\text { Tumor in } \\
\text { mammogram }\end{array}$} \\
\hline Size & Mean $(\mathrm{cm})$ & $6.2 \pm 1.9$ \\
\hline \multirow{3}{*}{ Visualization } & Two views & $64(75.3)$ \\
\hline & One view & $3(3.5)$ \\
\hline & Not visualized & $17(20)$ \\
\hline \multirow{3}{*}{$\begin{array}{l}\text { Reason for non- } \\
\text { visualizaton of } \\
\text { tumors }\end{array}$} & Dense parenchyma & $13(76.4)$ \\
\hline & Not visible on examination & $3(17.6)$ \\
\hline & Lack of perception & $1(6)$ \\
\hline
\end{tabular}

TNM: TNM staging system; IDC: invasive ductal carcinoma; ILC: invasive lobular carcinoma
The literature notes that mammography screening is performed in women over 40 years of age ${ }^{2}$. This study included women in a higher age group, but all had clinical evidence of a breast tumor, and the objective was to evaluate aspects associated with the non-visualization of tumors in the mammographic examination, demonstrating that breast density is an important factor, which is associated with age; however, age group was not seen to be an important factor here.

Several factors can influence non-visualization of tumors on mammography, and they can be grouped into four main ones ${ }^{3-6}$ :

Table 2. Radiological mammography findings.

\begin{tabular}{|c|c|c|}
\hline Radiological finding & Parameter & Value (\%) \\
\hline \multirow{4}{*}{ Parechyma } & $\begin{array}{l}\text { Lipo-substituted } \\
(0-25 \%)\end{array}$ & $30(35.3)$ \\
\hline & $\begin{array}{c}\text { Partially lipo- } \\
\text { substituted (25-50\%) }\end{array}$ & $33(38.8)$ \\
\hline & $\begin{array}{l}\text { Heterogeneously } \\
\text { dense }(51-75 \%)\end{array}$ & $15(17.6)$ \\
\hline & Dense (>75\%) & $7(8.2)$ \\
\hline \multirow{4}{*}{ Skin } & Normal & $33(38.8)$ \\
\hline & Retracted & $26(30.6)$ \\
\hline & Thickened & $20(23.5)$ \\
\hline & $\begin{array}{l}\text { Thickened + } \\
\text { retracted }\end{array}$ & $6(7.1)$ \\
\hline \multirow{5}{*}{ Nodule } & Spiculated & $27(31.8)$ \\
\hline & Irregular & $24(28.2)$ \\
\hline & Lobulated & $12(14.1)$ \\
\hline & No nodule & $15(17.6)$ \\
\hline & Regular & $7(8.2)$ \\
\hline \multirow{4}{*}{ Nodule border } & Irregular & $44(51.8)$ \\
\hline & Lobulated & $25(29.4)$ \\
\hline & Not visible & $14(16.5)$ \\
\hline & Regular & $2(2.4)$ \\
\hline \multirow{3}{*}{ Microcalcifications } & Absent & $52(61.2)$ \\
\hline & Pleomorphic & $11(12.9)$ \\
\hline & Other & $22(25.9)$ \\
\hline \multirow{4}{*}{$\begin{array}{l}\text { Microcalcification } \\
\text { distribution }\end{array}$} & Absent & $52(61.2)$ \\
\hline & Grouped & $19(22.4)$ \\
\hline & Segmented & $9(10.6)$ \\
\hline & Ductal & $5(5.9)$ \\
\hline \multirow{3}{*}{ Asymmetry } & Absent & $72(84.7)$ \\
\hline & Focal & $9(10.6)$ \\
\hline & Diffuse & $4(4.7)$ \\
\hline \multirow{4}{*}{ Lymph node } & Not visualized & $30(35.3)$ \\
\hline & Normal & $26(30.6)$ \\
\hline & Dense & $17(20)$ \\
\hline & Others & $12(14.1)$ \\
\hline
\end{tabular}


- patient (inherent or acquired dense breasts);

- tumor factors (minimal carcinoma, multifocal carcinoma and multicentric carcinoma);
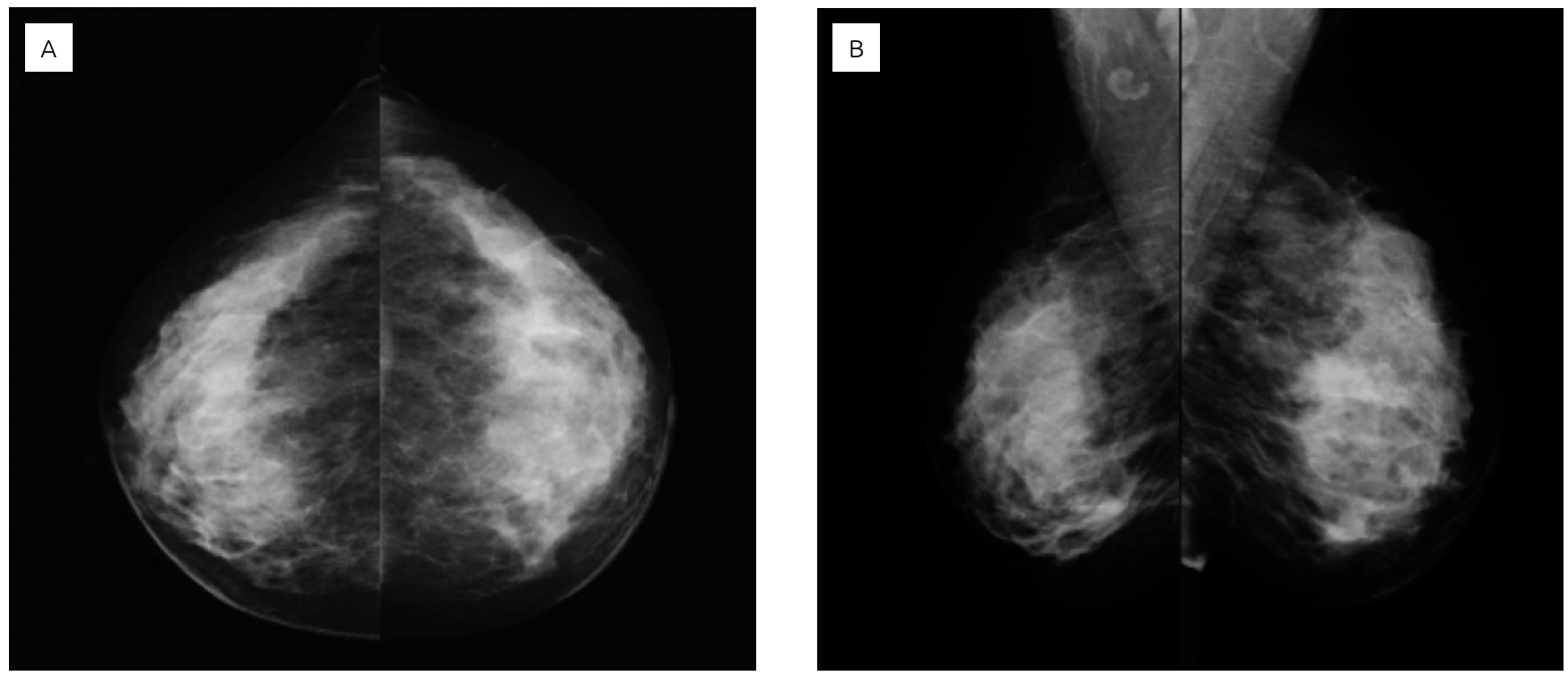

Figure 1. Mammography with no visible finding of tumor. Invasive ductal carcinoma in the left breast, T2N2M0 (stage IIIA).

Table 3. Factors related to non-identification of locally advanced breast cancer by mammography.

\begin{tabular}{|c|c|c|c|c|}
\hline Category & Variable & Not identified n (\%) & Identified n (\%) & p \\
\hline \multicolumn{5}{|l|}{ Clínical } \\
\hline Size & Mean+SD & $7.3 \pm 3.2$ & $6.8 \pm 2.3$ & 0.83 \\
\hline \multirow{3}{*}{ Age group } & $<40$ & $5(20)$ & $20(80)$ & \multirow{3}{*}{0.74} \\
\hline & 40 to 49 & $7(24.1)$ & $22(75.9)$ & \\
\hline & $\geq 50$ & $5(16.1)$ & $26(83.9)$ & \\
\hline \multirow{3}{*}{ Histology } & IDC & $16(21.9)$ & $57(78.1)$ & \multirow{3}{*}{0.46} \\
\hline & ILC & 0 & $5(100)$ & \\
\hline & Others & $1(14.3)$ & $6(85.7)$ & \\
\hline \multirow{2}{*}{ N-TNM } & N0-1 & $13(19.1)$ & $55(80.9)$ & \multirow{2}{*}{0.74} \\
\hline & N2-3 & $4(23.5)$ & $13(76.5)$ & \\
\hline \multicolumn{5}{|l|}{ Mammography } \\
\hline \multirow{3}{*}{ Parenchyma } & $0-25 \%$ & $3(10)$ & $27(90)$ & \multirow{3}{*}{0.04} \\
\hline & $51-75 \%$ & $6(40)$ & $9(60)$ & \\
\hline & $>75 \%$ & $3(42.9)$ & $4(57.1)$ & \\
\hline \multirow{2}{*}{ Skin } & Normal & $5(15.2)$ & $28(84.8)$ & \multirow{2}{*}{0.42} \\
\hline & Anormal & $12(70.6)$ & $40(76.9)$ & \\
\hline \multirow{2}{*}{ Nodule } & No nodule & $5(33.3)$ & $10(66.7)$ & \multirow{2}{*}{0.17} \\
\hline & Nodule & $12(17.1)$ & $58(82.9)$ & \\
\hline \multirow{2}{*}{ Microcalcification } & Absent & $12(23.1)$ & $40(76.9)$ & \multirow{2}{*}{0.42} \\
\hline & Pathological & $5(15.2)$ & $28(80)$ & \\
\hline \multirow{2}{*}{ Lymph node } & Absent/not visualized & $13(23.2)$ & $43(76.8)$ & \multirow{2}{*}{0.40} \\
\hline & Altered & $4(13.8)$ & $25(86.2)$ & \\
\hline
\end{tabular}

N-TNM: nodal TNM stage; SD: standard deviation; IDC: invasive ductal carcinoma; ILC: invasive lobular carcinoma 
- factors related to mammographic evaluation (poor perception and misinterpretation.

Even in the presence of negative radiological findings, mammographic screening is associated with the presence of interval tumors, which can be divided into true tumors, minimal findings and false negative tests (underestimation of radiological findings), making additional examinations and systematic clinical evaluation necessary, a fact that should determine the search for a professional, with the aim of repeating the examinations or combination of complementary examinations ${ }^{16}$. Microcalcifications and asymmetries can go unnoticed, needing attention ${ }^{17}$.

Regular audits are needed to improve the technical quality of the radiological examination, minimizing potential causes of false negatives ${ }^{18}$. All patients, despite having undergone previous mammography, were systematically submitted to a new mammography examination at the service, which adheres to strict radiological quality programs, being accredited by the Brazilian Society of Radiology and, more recently, having undergone an international audit.

The type of equipment used can influence radiological findings, thereby interfering with the addition of radiological assessment software. Computer-aided detection $(\mathrm{CAD})^{19}$ raises sensitivity by $10 \%$, for example. Mammographic screening studies were performed using conventional mammography, but digital mammography allows better visualization, although it has not been shown to be superior in mammographic screening ${ }^{20}$. Also, it decreases the incidence of interval tumors ${ }^{21}$.

Two technologies are increasingly present in our daily lives: tomosynthesis ${ }^{19}$, which improves sensitivity mainly in dense breasts; and spectral mammography, which increases sensitivity and specificity in relation to digital mammography (86.2-94.1\% versus $53.4-85.9 \%)^{22}$. In this study, all mammograms were analog, and the examinations were evaluated by three radiologists with experience in mammographic screening, which enhances the importance of the findings presented here. Double-reading mammographic evaluation and evaluation by a senior radiologist decrease the rates of false negatives, compared to simple reading. Double-reading minimizes potential errors in perception and interpretation. In this sense, there is discussion regarding the possibility of simple reading with tomosynthe$\mathrm{sis}^{5}$, where the negative points would be the increase in radiation of the breast and the cost of the equipment.

Some radiological findings are associated with non-visualization of tumors on mammography, such as architectural distortion, asymmetries, unsuspected densities, anatomical location, lobular carcinoma, dense breast and lesion size $\mathrm{e}^{3,23}$. In this study, the only factor that was associated with failure to identify the tumor was breast density.

Despite the small number of patients evaluated $(n=85)$, we found a substantial number of mammograms with a negative finding (20\%), even after evaluation by experienced radiologists and examinations performed under appropriate technical conditions, with internal clinical quality control, which denotes the importance of including and valuing clinical findings and the patient's clinical history.

Currently, when discussing mammographic screening, patients should be aware of the pros and cons of mammographic screening, but we must stress that it needs to be performed in asymptomatic patients. Clinical examination increases the detection rate $^{24}$, or minimizes negative radiological findings ${ }^{25}$. Symptomatic patients should seek out diagnostic services. Positive or doubtful clinical findings should warrant additional examinations, with ultrasound being an important complementary examination to be initially considered ${ }^{6}$. A study evaluating the potential reasons for non-visualization of tumors on mammography, given the identification of lesions by ultrasound, considered potential mammographic interpretation errors to be the presence of asymmetries, distortions and calcifications ${ }^{18}$.

As limitations of the study, the radiological examinations were performed using conventional mammography, but nowadays in Brazil, most mammography uses this equipment, which reinforces our findings.

In the United States, radiology is the eighth specialty associated with medical procedures, and it is often related to problems of perception or interpretation ${ }^{21}$. The dissemination of knowledge about the limitations of mammography and the improvement of the doctor-patient relationship can minimize potential factors that can limit the radiological examination.

Mammography is one of the main tests related to the decrease in breast cancer mortality, a fact that should be valued. Increasingly, the patient must be aware of the pros and cons of mammographic screening and the limitations of mammography ${ }^{1,2}$, in addition to the factors discussed in this article. Limitations should be part of the mammographic report, aiming at better knowledge on the part of the patient. Strict quality control, audited clinics and double reading can minimize the risk. This is associated with the presence of clinical history and clinical notes, which can influence the radiological report, and in the present study both were essential for the diagnosis of lesions not seen on mammography.

\section{CONCLUSION}

Rigorous observation after the mammographic examination, through clinical history, physical examination and image reading, must be considered in the radiological report, with the aim of reducing false negative rates. In this study, high breast density was the greatest obstacle, highlighting the importance of examining secondary aspects. The presence of asymmetries, distortions, changes in skin thickness and involvement of lymph 
nodes is a warning sign that should be considered important, even in the case of no description of clinical findings.

\section{AUTHORS' CONTRIBUTION}

A.H.U.W.: conceptualization, data curation, formal analysis, funding investigation, methodology, project administration, supervision, validation.
M.M.S.: data curation, formal analysis, investigation, methodology.

B.E.F.C.: data curation, formal analysis, investigation, methodology. R.A.C.V.: conceptualization, data curation, formal analysis, funding acquisition, investigation, project administration, resources, supervision.

All authors contribute to writing-original draft and performed writing-review \& editing.

\section{REFERENCES}

1. Loberg M, Lousdal ML, Bretthauer M, Kalager M. Benefits and harms of mammography screening. Breast Cancer Res. 2015;17(1):63. http://doi.org/10.1186/s13058-015-0525-z

2. Kopans DB. Arguments against mammography screening continue to be based on faulty science. Oncologist. 2014;19:10712. http://dx.doi.org/10.1634/theoncologist.2013-0184

3. Kamal RM, Abdel Razek NM, Hassan MA, Shaalan MA. Missed breast carcinoma; why and how to avoid? J Egypt Natl Canc Inst. 2007;19(3):178-94.

4. Choi WJ, Cha JH, Kim HH, Shin HJ, Chae EY. Analysis of prior mammography with negative result in women with interval breast cancer. Breast Cancer. 2016;23(4):583-9. https://doi. org/10.1007/s12282-015-0606-y

5. Wadhwa A, Sullivan JR, Gonyo MB. Missed Breast Cancer: What Can We Learn? Curr Probl Diagn Radiol. 2016;45(6):40219. https://doi.org/10.1067/j.cpradiol.2016.03.001

6. Majid AS, de Paredes ES, Doherty RD, Sharma NR, Salvador X. Missed breast carcinoma: pitfalls and pearls. Radiographics. 2003;23(4):881-95. https://doi.org/10.1148/rg.234025083

7. Vieira R, Formenton A, Bertolini SR. Breast cancer screening in Brazil. Barriers related to the health system. Rev Assoc Med Bras. 2017;63(5):466-74. http://dx.doi.org/10.1590/18069282.63.05.466

8. Vieira RA, Lourenço TS, Mauad EC, Moreira Filho VG, Peres SV, Silva TB, et al. Barriers related to non-adherence in a mammography breast-screening program during the implementation period in the interior of Sao Paulo State, Brazil. J Epidemiol Glob Health. 2015;5(3):211-9. https://doi. org/10.1016/j.jegh.2014.09.007

9. Lee BL, Liedke PE, Barrios CH, Simon SD, Finkelstein DM, Goss PE. Breast cancer in Brazil: present status and future goals. Lancet Oncol. 2012;13(3):e95-e102. https://doi.org/10.1016/ S1470-2045(11)70323-0

10. Medeiros GC, Bergmann A, Aguiar SS, Thuler LC. [Determinants of the time between breast cancer diagnosis and initiation of treatment in Brazilian women]. Cad Saúde Pública. 2015;31(6):1269-82. http://dx.doi.org/10.1590/0102-311X00048514
11. George SA. Barriers to breast cancer screening: an integrative review. Health Care Women Int. 2000;21(1):53-65. https://doi. org/10.1080/073993300245401

12. Vieira RAM, Mauad EC, Zucca-Mattheus AG, Mattos JSC, Haikel Jr. RL, Bauab SP. Breast screening: begining-middle-end Rev Bras Mastol. 2010;20(2):92-7.

13. Bleicher RJ. Timing and Delays in Breast Cancer Evaluation and Treatment. Ann Surg Oncol. 2018;25(10):2829-38. https:// doi.org/10.1245/s10434-018-6615-2

14. Tramonte MS, Silva PCS, Chubaci SR, Cordoba CCRC, ZuccaMatthes AG, Vieira RAC. Delay in diagnosis of breast cancer in a public oncologic hospital. Medicina (Ribeirão Preto). 2016;49(5):451-62. http://dx.doi.org/10.11606/issn.2176-7262. v49i5p451-462

15. Vieira IT, de Senna V, Harper PR, Shahani AK. Tumour doubling times and the length bias in breast cancer screening programmes. Health Care Manag Sci. 2011;14(2):203-11. https://doi.org/10.1007/s10729-011-9156-9

16. Watanabe AHU, Vieira RAC, Sabino SMPS, Zucca-Matthes AG. Interval cancer in breast cancer screening program. Câncer de intervalo em rastreamento mamográfico. Rev Bras Mastol. 2013;23(1):28-32.

17. Lekanidi K, Dilks P, Suaris T, Kennett S, Purushothaman H. Breast screening: What can the interval cancer review teach us? Are we perhaps being a bit too hard on ourselves? Eur J Radiol. 2017;94:13-5. https://doi.org/10.1016/j.ejrad.2017.07.005

18. Haq R, Lim YY, Maxwell AJ, Hurley E, Beetles U, Bundred S, et al. Digital breast tomosynthesis at screening assessment: are two views always necessary? Br J Radiol. 2015;88(1055):20150353. https://doi.org/10.1259/bjr.20150353

19. Ariaratnam NS, Little ST, Whitley MA, Ferguson K. Digital breast Tomosynthesis vacuum assisted biopsy for Tomosynthesis-detected Sonographically occult lesions. Clin Imaging. 2018;47:4-8. https://doi.org/10.1016/j. clinimag.2017.08.002

20. Skaane P. Studies comparing screen-film mammography and full-field digital mammography in breast cancer screening: updated review. Acta Radiol. 2009;50(1):3-14. https://doi. org/10.1080/02841850802563269 
21. Harvey HB, Tomov E, Babayan A, Dwyer K, Boland S, Pandharipande PV, et al. Radiology Malpractice Claims in the United States From 2008 to 2012: Characteristics and Implications. J Am Coll Radiol. 2016;13(2):124-30. https://doi. org/10.1016/j.jacr.2015.07.013

22. Mori M, Akashi-Tanaka S, Suzuki S, Daniels MI, Watanabe C, Hirose M, et al. Diagnostic accuracy of contrast-enhanced spectral mammography in comparison to conventional fullfield digital mammography in a population of women with dense breasts. Breast Cancer. 2017;24(1):104-10. https://doi. org/10.1007/s12282-016-0681-8

23. Bazzocchi M, Facecchia I, Zuiani C, Puglisi F, Di Loreto C, Smania S. [Diagnostic imaging of lobular carcinoma of the breast: mammographic, ultrasonographic and MR findings]. Radiol Med. 2000;100(6):436-43.

24. Bancej C, Decker K, Chiarelli A, Harrison M, Turner D, Brisson J. Contribution of clinical breast examination to mammography screening in the early detection of breast cancer. J Med Screen. 2003;10(1):16-21. https://doi. org/10.1258/096914103321610761

25. Mouchawar J, Taplin S, Ichikawa L, Barlow WE, Geiger AM, Weinmann S, et al. Late-stage breast cancer among women with recent negative screening mammography: do clinical encounters offer opportunity for earlier detection? J Natl Cancer Inst Monogr. 2005;(35):39-46. https://doi.org/10.1093/ jncimonographs/lgi036 